\title{
Prediction of psychological functioning one year after the predictive test for Huntington's disease and impact of the test result on reproductive decision making
}

\begin{abstract}
Marleen Decruyenaere, Gerry Evers-Kiebooms, Andrea Boogaerts, Jean-Jacques Cassiman, Trees Cloostermans, Koen Demyttenaere, René Dom, Jean-Pierre Fryns, Herman Van den Berghe
\end{abstract}

Huntington's disease (HD) is a neurodegenerative disease, characterised by involuntary movements (chorea), progressive dementia, and affective disturbances (for example, aggression, paranoia). This is caused by a selective and progressive neuronal degeneration in the basal ganglia and cerebral cortex. ${ }^{1}$ The age at onset is about 35 to 50 years. HD is inherited as an autosomal dominant trait, with the HD gene localised on the short arm of chromosome 4 . The $50 \%$ risk of getting HD may be very stressful and may influence decisions concerning education, marriage, child bearing, and career. Predictive DNA testing for Huntington's disease has been available as a clinical service since 1987 , initially by DNA linkage and since mid-1993 by direct mutation analysis. ${ }^{2-4}$ In the Centre for Human Genetics in Leuven, predictive test requests are approached multidisciplinarily by a team consisting of a genetic counsellor, a psychologist, a psychiatrist, a neurologist, and a social worker. During the counselling sessions, full information is provided on $\mathrm{HD}$ and on the predictive test. The role and psychological meaning of the disease and the test in the life of those tested are explored. After the disclosure of the predictive test result, short and long term emotional and social support are provided. A full description of the approach has been reported by Evers-Kiebooms ${ }^{5}$ and Decruyenaere et al. ${ }^{6}$

Subjects tested seem to be self-selected and mentally resourceful. ${ }^{6-11}$ Kessler $^{11}$ hypothesised that Barron's psychological construct "ego strength"12 differentiates between test participants and non-participants. Pretest psychometric testing ${ }^{6}$ showed that many psychological characteristics did not differ from those of the general population: most test applicants had a normal psychological profile and anxiety. and depression levels were not significantly different from those of the general population. Those tested were, however, significantly more socially extroverted and had a significantly higher ego strength than the general population. They also had more positive coping strategies: active coping, palliative reactions, social support seeking, and comforting ideas.

Some authors ${ }^{11}{ }^{13}{ }^{14}$ have raised the question of how the group of people who have had direct testing might differ from those who have had linkage testing, not only with regard to their family interactions and resourcefulness, but
Key words: Huntington's disease; predictive testing; psychology.

\begin{abstract}
taken into account when predicting individual post-test reactions.

(F Med Genet 1996;33:737-743)

Abstract
For people at risk for Huntington's dis-
\end{abstract}


also with regard to their psychological functioning after a test result, but this has not been tested in previously published studies.

Studies on the psychological impact of the predictive test result have reported, in general, a low rate of psychiatric reactions. ${ }^{915-20}$ Common sense might expect positive effects of a good result and negative effects of a bad result. The test outcome has, however, a mixture of positive and negative consequences, which may vary over time. For instance, Bloch et $a l^{16}$ and Huggins $e t$ al $^{17}$ found that symptoms of depression and anxiety were most common in carriers in the first two months, but after one year the depression levels have fallen back to the baseline level. They became more centred in the present and had greater difficulty in planning for the future. While most persons receiving a decreased risk for HD had fewer depressive symptoms, approximately $10 \%$ needed additional counselling. The most vulnerable time was between two and 12 months after the test. In particular, those who received a test result contradictory to the consciously or unconsciously expected outcome had difficulty in adjusting to the test result. Wiggins et $a l^{9}{ }^{9}$ using the General Severity Index from the Symptom Checklist, ${ }^{21}$ the Beck Depression Inventory, ${ }^{22}$ and the General Well-Being Scale, ${ }^{23}$ concluded that knowing one's carrier status reduced uncertainty and provided an opportunity for appropriate planning. Codori et $a l^{10}$ observed that the majority of persons tested felt relief from uncertainty. A negative effect in carriers was psychological burden (worry, guilt). Nevertheless, they focused more on what they had gained and on their strategies for coping with the bad news than on the adverse effects, which was considered as an adaptive response to overwhelming knowledge. One of the conclusions of the research of Tibben et $a l^{4}$ was that, six months after the test, carriers reacted with denial or minimisation of the impact of the test outcome; most of them rated their current life situation as being very good. The test result did not increase the previously expected control over their future. Another observation was that some noncarriers had to adjust to the sudden removal of the Huntington scenario: they reacted with absence of relief and emotional numbness. Effects of predictive testing on the partner relationship have been discussed by Demyttenaere $e t a l^{25}$ and Quaid and Wesson. ${ }^{20}$

The aim of the present paper is two-fold. First, we wished to evaluate the impact of the predictive test on the psychological condition of people tested, using psychometric tests (general anxiety, depression level, and personality profile, including ego strength), and on their reproductive decisions, one year after the test. Reduction of uncertainty and family planning decisions proved to be important motives for requesting the test. ${ }^{6}$ We question whether knowing one's carrier status indeed reduces uncertainty and anxiety and whether it facilitates reproductive decision making. Second, the paper endeavours to identify predictors of psychological adaptation (psychometric evaluation of general anxiety, depression level, and ego strength) one year after the predictive test. The candidate predictive variables consisted of the tested subjects' pretest psychological characteristics, gender, age, and test result. Until now, there have been no published studies about the prediction of psychological adaptation one year after HD testing by means of psychometric tests. The findings may help the counsellor to an early detection of those at risk for post-test anxiety or depressive symptoms.

\section{Material and methods}

SUBJECTS

The target group of the study consisted of people tested who received a predictive test result in a genetic centre in Flanders before April $1994(n=57)$. During pretest counselling, test applicants were informed about the set up of a longitudinal study concerning the impact of the predictive test on people's life. They all agreed that their psychometric tests and interview data could also be used for research purposes. For 53 of them complete follow up data were available: 31 with a favourable and 22 with an unfavourable result. The drop outs were two carriers and two non-carriers who were not interested in follow up counselling one year after the test. For 34 persons, the test result was obtained by linkage analysis. Immediately after the identification of the gene they were informed by letter about the possibility of direct testing; three of them (two carriers and one non-carrier) asked for a confirmation of the initial result. This may be explained by the fact that in our centre indirect testing was only performed after a preceding DNA analysis in the family had shown that a high level of informativity could be expected. Otherwise, those tested did not proceed in the test programme and no blood sample was taken for analysis. Moreover the age adjusted risk after testing was very close to $99 \%$ or $1 \%$ except in a few cases. In the latter, much more attention was given to the nature of the risk modification after the disclosure of the test result. All test applicants were very well informed about the small level of residual uncertainty, but they subjectively evaluated their result in a binary way "carrier" or "non-carrier".

Table 1 presents some of the sociodemographic data. The mean age of the carriers is 33.9 years (range 24-50) and of the noncarriers 34.1 years (range 22-76); the difference is not significant (two tailed $t$ test). The direct testing group did not differ significantly from the linkage group in these sociodemographic variables (chi-square and Kolmogorov-Smirnov test for independent samples ${ }^{26}$ and two tailed $t$ test).

French or German speaking subects tested $(n=3)$ were excluded from the psychometric analyses since no appropriate tests or norms were available. The statistical analyses were performed on the group with a $50 \%$ prior risk. The group with a $25 \%$ risk was too small $(n=4)$ to analyse.

\section{METHODS}

To assess pre- and post-test psychological characteristics, the following psychometric 
questionnaires were administered during pretest and follow up counselling. The STAI (State Trait Anxiety Inventory ${ }^{27}$ ) contains two scales: general anxiety (STAI trait) and situational anxiety (STAI state or, in the context of this study, anxiety during the counselling sessions). The BDI (Beck Depression Inventory $^{28}$ ) assesses the depression level of a person. Situational anxiety (STAI state) and BDI were administered in the pretest period as well as one month and one year after the predictive test. General anxiety (STAI trait) was administered in the pretest period and one year after the test.

The MMPI (Minnesota Multiphasic Personality Inventory ${ }^{29}{ }^{30}$ ) was used to assess general personality in the pretest period and one year after the test. We used the standard scales (see Results section, table 2) and one supplementary scale, ego strength or general capacity for personality integration, developed by Barron. ${ }^{12}$ The MMPI scores are represented as $\mathrm{T}$ scores (mean 50, SD 10); they are corrected in order to limit the effect of defensive responding $\left(\mathrm{K}\right.$ correction $\left.^{29}\right)$. Norms for a Dutch translation of the MMPI have been calculated on a combined Dutch and Flemish sample.

Last, but not least, the UCL (Utrechtse Coping Lijst $\left.{ }^{31}\right)$, a Dutch adaptation of the Westbrook Coping Scale, ${ }^{32}$ was administered in the pretest period to evaluate coping strategies: active coping, palliative coping, avoiding reactions, social support seeking, depressiveregressive coping, expression of emotions or anger, and comforting ideas.

Table 1 Sociodemographic characteristics of the people who received a predictive test result more than one year ago

\begin{tabular}{lll}
\hline & $\begin{array}{l}\text { Non-carrier } \\
(n=31)\end{array}$ & $\begin{array}{l}\text { Carrier } \\
(n=22)\end{array}$ \\
\hline Gender & 10 & \\
$\quad$ Male & 12 & 10 \\
$\quad$ Female & 21 & \\
Marital status and family size & 7 & 3 \\
$\quad$ Unmarried & 9 & 9 \\
$\quad$ Married, no children & 15 & 10 \\
$\quad$ Married, children & 15 & 12 \\
$\begin{array}{l}\text { Desire for children (pretest period) } \\
\text { Yes }\end{array}$ & 2 & 1 \\
$\quad$ Undecided & 14 & 9 \\
$\quad$ No & 4 & 0 \\
Education & 15 & 12 \\
$\quad<$ High school & 12 & 10 \\
$\quad$ High school & & \\
$\quad>$ High school & & \\
\hline
\end{tabular}

Table 2 Mean scores for pre-and post-test state and trait anxiety (STAI), for depression $(B D I)$, and for Barron's ego strength scale of carriers $(n=22)$ and non-carriers $(n=24)$

\begin{tabular}{llll}
\hline & Pretest (mean $(S D))$ & $\begin{array}{l}\text { One month later } \\
(\text { mean }(S D))\end{array}$ & $\begin{array}{l}\text { One year later (mean } \\
(S D))\end{array}$ \\
\hline $\begin{array}{l}\text { Carriers } \\
\text { STAI state }\end{array}$ & $34.9(8.5)$ & $34.5(11.3)$ & $32.7(8.8)$ \\
STAI trait & $34.1(6.9)$ & & $33.7(10.1)$ \\
BDI & $3.6(4.2)$ & $3.4(4.5)$ & $2.3(2.5)$ \\
$\quad$ Ego strength & $60.5(7.2)$ & & $60.8(7.7)$ \\
Non-carriers & $37.1(8.1)$ & $32.8^{\star}(8.3)$ & $31.4 \dagger(7.6)$ \\
STAI state & $38.4(10.8)$ & & $34.2^{\star}(7.9)$ \\
STAI trait & $6.2(8.7)$ & $2.6 \dagger(4.0)$ & $2.5^{\star}(3.1)$ \\
BDI & $56.0(13.0)$ & & $57.7(14.0)$ \\
Ego strength & &
\end{tabular}

* The difference between the pre- and post-test mean is significantly different from zero, with alpha $=0.05$.

t The difference between the pre- and post-test mean is significantly different from zero, with alpha $=0.01$.
Data on reproductive decisions were gathered during the counselling session one year after the test.

\section{Results}

ANXIETY, DEPRESSION LEVEL, AND GENERAL PERSONALITY PROFILE, INCLUDING EGO STRENGTH, ONE YEAR AFTER THE TEST

The mean scores for state and trait anxiety (STAI), for depression (BDI), and for Barron's ego strength (MMPI) in the follow up period, as well as in the pretest period, are presented in table 2. For the non-carriers, the mean for situational anxiety (STAI state), general anxiety (STAI trait), and depression level (BDI) was significantly decreased one month and one year after the test result (two tailed $t$ tests). Their mean scores on the MMPI standard clinical scales (not in the table) and on Barron's ego strength scale were not significantly changed. For the carriers, there were no significant differences at all between the preand the post-test period.

The differences between carriers and noncarriers were not significant, in either the pretest period or the post-test period. Moreover the linkage and the direct testing groups did not significantly differ from each other with regard to pre- and post-test psychological characteristics.

Individual psychometric scores were used to identify the test applicants with at least a mild depression level (BDI $>10$ ) or a high score for anxiety (STAI trait >decile 8), or both, one year after the test. Table 3 presents an overview of the test result and some pre- and post-test scores of the five selected subjects. The first person is an unmarried woman ( 31 years) who lived with her father and had had some failed relationships. She had a history of asthma attacks since she was informed of her $50 \%$ risk (about 15 years ago). After the test, the symptoms of asthma had increased. She also had relationship problems with her father at that time. The second subject is a married woman (38 years) with three children. Her life was severely marked by the divorce of her parents during childhood, the rift with her affected father, anxiety about getting the disease, and guilt feelings towards her children. After the test, she felt better, but she still had a lot of anxieties and psychosomatic complaints. Subject 3 is a woman ( 28 years, no children) who had an immature relationship with her husband. One year after getting a good test result, she complained of back pain, headache, and fatigue. She became extremely involved in helping her parents and others at risk for HD; this may be a reaction to unconscious survivor guilt. Subject 4 is a man ( 30 years), unmarried, but having a stable relationship for two years. One year after the test the relationship broke up. This was not unexpected; during the pretest period they claimed that they did not know whether their relationship would survive a positive test result. The last person is a married man (38 years) who reported vague somatic complaints but no manifest high anxiety. After receiving the bad news, he was 
Table 3 Scores of five subjects with mild depression level or high anxiety or both one year after the test

\begin{tabular}{lllllll}
\hline Result & Pretest BDI & Post-test $B D I$ & $\begin{array}{l}\text { Pretest STAI } \\
\text { trait }\end{array}$ & $\begin{array}{l}\text { Post-test } \\
\text { STAI trait }\end{array}$ & $\begin{array}{l}\text { Pretest ego } \\
\text { strength }\end{array}$ & $\begin{array}{l}\text { Post-test ego } \\
\text { strength }\end{array}$ \\
\hline Non-carrier & 7 & 12 & 40 & 46 & 56 & 48 \\
Non-carrier & 16 & 6 & 53 & 51 & 29 & 37 \\
Non-carrier & 11 & 6 & 47 & 50 & 51 & 43 \\
Carrier & 8 & 4 & 29 & 49 & 64 & 64 \\
Carrier & 1 & 4 & 40 & 52 & 59 & 46 \\
\hline
\end{tabular}

preoccupied by symptom seeking, by fear of failure at work, and of becoming aggressive towards his wife and children in the future.

\section{REPRODUCTIVE DECISIONS ONE YEAR AFTER THE TEST \\ Carriers}

One year after testing, four of the 13 couples who had considered procreation before the test had chosen to refrain from (further) reproduction; this was in line with their pretest choice should they prove to be a gene carrier. Two of these couples had no children yet, the other couples had two and three children, respectively. Four couples had a pregnancy with prenatal diagnosis for HD or were pregnant and planned a prenatal test. Before testing, three of them had planned to have children with prenatal diagnosis in the case of being a carrier, while the other couple was undecided about reproduction at that time. These four couples had no children when starting the test. One year after the test, five carriers were undecided with regard to reproduction. The pretest anticipation in the case of being a carrier of these five subjects was: giving up reproduction (two persons; no children yet in the pretest period), sterilisation (one person; already had one child), and undecided (two persons; no children yet).

\section{Non-carriers}

One year after receiving a good test result, five non-carrier couples had a newborn baby and three couples were pregnant (five of these eight couples already had children before the test). One of these eight couples had a prenatal test because of advanced maternal age. Another woman was already pregnant before she received her test result. This couple had stopped contraception some months before the communication of the test result, but they did not plan a pregnancy until they knew the test outcome. Had the woman proven to be a gene carrier, they would not have terminated the pregnancy. One couple had a spontaneous miscarriage because of a fetal chromosomal anomaly. Three married and two single test applicants said that they planned to have children in the future. One of the above 14 persons was undecided about reproduction before the test; the others had planned to have children in the case of a good test result. One couple decided after the test to have no children; before the test they were undecided (they had a history of subfertility). In two persons who were undecided about reproduction in the pretest period, the indecision persisted.

PREDICTION OF POST-TEST ANXIETY, DEPRESSION, AND EGO STRENGTH

In order to select the best predictors of individual post-test general anxiety, depression level, and ego strength, we performed stepwise multiple regression analyses. Regression analysis is the analysis of the relationship between one variable and another set of variables, taking into account the correlation between this set of variables. The Pearson correlations between the pretest psychometric measures (predictor variables) and the post-test criterion variables are presented in table 4 . Predictive test result, gender, and age did not correlate significantly with the post-test variables.

When performing a regression analysis the response variable (criterion) is expressed as a linear function of regressor variables (predictors) and parameters. The coefficient of deter-

Table 4 Pearson correlations of pretest psychometric variables with post-test anxiety, depression level, and ego strength $(n=46)$

\begin{tabular}{lllll}
\hline Pretest scores & STAI state after 1 year & STAI trait after 1 year & BDI after 1 year & Ego strength after 1 year \\
\hline STAI state & NS & $0.31^{\star}$ & $0.33^{\star}$ & $-0.46^{\star \star}$ \\
STAI trait & NS & $0.47^{\star \star \star}$ & $0.55^{\star \star \star}$ & $-0.63^{\star \star \star}$ \\
BDI & NS & $0.35^{\star}$ & $0.57^{\star \star \star}$ & $-0.46^{\star \star}$ \\
Ego strength & NS & $-0.53^{\star \star \star}$ & $-0.56^{\star \star \star}$ & $0.76^{\star \star \star}$ \\
Hypochondria & NS & $0.30^{\star}$ & $0.45^{\star \star \star}$ & $-0.31^{\star \star}$ \\
Depression & NS & $0.38^{\star \star}$ & $0.56^{\star \star \star}$ & $-0.52^{\star \star \star}$ \\
Hysteria & NS & NS & $0.46^{\star \star}$ & $-0.33^{\star}$ \\
Psychop dev & NS & NS & NS & NS \\
Masc/femin & NS & NS & NS & $-0.30^{\star}$ \\
Paranoia & NS & NS & NS & $-0.30^{\star}$ \\
Psychasthenia & NS & $0.33^{\star}$ & NS & $-0.49^{\star \star \star}$ \\
Schizophrenia & NS & $0.32^{\star}$ & NS & $-0.49^{\star \star \star}$ \\
Hypomania & NS & NS & $0.43^{\star \star}$ & NS \\
Social introv & NS & NS & NS & $-0.54^{\star \star \star}$ \\
Active coping & NS & NS & NS & NS \\
Palliative coping & NS & NS & NS & NS \\
Avoiding & NS & $0.42^{\star \star}$ & NS & $0.39^{\star}$ \\
Social support & NS & NS & NS & $-0.51^{\star \star \star \star}$ \\
Depressive coping & NS & $-0.35^{\star}$ & NS & NS \\
Exp emotions & NS & NS & & NS \\
Comforting ideas & NS & & \\
\hline
\end{tabular}


Table 5 Stepwise regression analyses with post-test general anxiety (STAI trait), depression level (BDI), and ego strength (Barron's scale) as criteria. (A) Results of step $1 ;(B)$ results after step $3(n=46)$

\begin{tabular}{llr}
\hline Criterion (post-test) & Regression equation (pretest) & $R^{2}\left(\operatorname{Adj} R^{2}\right) ; p$ \\
\hline (A) & & $0.29(0.25) ; \mathrm{p}<0.001$ \\
Trait anxiety (STAI trait) & $59.5-0.44$ Ego strength & $0.37(0.34) ; \mathrm{p}<0.001$ \\
Depression (BDI) & $6.49-0.08$ Ego strength +0.14 BDI & $0.57(0.55) ; \mathrm{p}<0.001$ \\
Ego strength (Barron) & $13.3+0.79$ Ego strength & $0.35(0.32) ; \mathrm{p}<0.001$ \\
(B) & $70.21-0.04$ Ego strength -0.93 Comf ideas (UCL) & $0.39(0.37) ; \mathrm{p}<0.001$ \\
Trait anxiety (STAI trait) & $-1.98+0.14$ BDI + 0.08 Depression (MMPI) & $0.57(0.55) ; \mathrm{p}<0.001$ \\
Depression (BDI) & $13.3+0.79$ Ego strength & \\
Ego strength (Barron) &
\end{tabular}

mination, or $\mathrm{R}^{2}$, is the proportion of the variance in the criterion that is accounted for by the predictors of the equation; the larger the. $\mathrm{R}^{2}$, the better the fit of the model with the data. The adjusted $R^{2}$ is the $R^{2}$ adjusted for the number of predictors and sample size. Because of the small size of the group studied $(n=46)$, the regression analyses were performed in different phases, each phase with maximum four predictors included in the regression model (always with post-test general anxiety, depression level, and ego strength as criterion variables).

First of all, the regression analyses were performed with pretest general anxiety, depression level, and ego strength as predictors, because of their high correlations with the criterion variables. The regression equations and the (adjusted) coefficient of determination $\mathrm{R}^{2}$ are presented in table 5A. Post-test trait anxiety (STAI trait) was best predicted by pretest ego strength (adjusted $\mathrm{R}^{2}=0.25, \mathrm{p}<0.001$ ). Pretest depression level (BDI) and ego strength were the best predictors for the post-test depression level (BDI) (adjusted $\mathrm{R}^{2}=0.34$, $\mathrm{p}<0.001$ ). The negative sign of the pretest variable ego strength in these two equations indicates that the post-test general anxiety and post-test depression level will decrease as pretest ego strength increases. Pretest ego strength was the single best predictor of post-test ego strength (adjusted $\mathrm{R}^{2}=0.55$, $\mathrm{p}<0.001$ ).

Second, the UCL scales were added one by one in the three regression equations of table $5 \mathrm{~A}$ and successive stepwise regression analyses were performed. Post-test depression level and ego strength could not be better predicted if a coping strategy, measured by the UCL, was added, so it was not necessary to adapt the regression equations of the first step. Post-test general anxiety was, however, significantly better predicted by a combination of pretest ego strength and the coping strategy comforting ideas (adjusted $\mathrm{R}^{2}=0.32, \mathrm{p}<0.001$; table 5B).

Third, the MMPI scales were included one by one in the regression equations of the second step. None of them added a significant contribution to predicting post-test trait anxiety and ego strength. For the prediction of post-test depression level, however, the stepwise regression analysis selected the pretest depression level (BDI) and the pretest depression scale of the MMPI as best predictors and removed ego strength from the regression equation (adjusted $R^{2}=0.37, p<0.001$; table 5B).
Fourth, we investigated whether the result of the predictive test (carrier/non-carrier) had an additional predictive value, besides the pretest psychometric measures already in the model in step 3. The proportion of variance accounted for did not significantly increase. We also found no significant increase in the explained variance when gender or age were included in the predictive model.

\section{Discussion}

In this paper, we present follow up data for the first year after the predictive test in the group of subjects who received a result in a genetic centre in Flanders. Although the sample size is small, the study shows some general trends at a group level. On average, receiving bad news had no significant impact on anxiety, depression level, or personality, as measured in this study. In other words, in general, the certainty of being a carrier seemed no worse or better than uncertainty about one's carrier status. For non-carriers, however, knowing was, on average, better than not knowing: the mean anxiety and depression levels had significantly decreased one year after the test. Mean ego strength and personality profile did not significantly change. It is important to keep in mind that averages mask individual reactions. $\mathrm{Al}$ though there have been no psychiatric problems, about $10 \%$ of the subjects tested, carriers as well as non-carriers, had a mild depression level or a high level of trait anxiety, or both, in the post-test period. In general, test applicants with pre- or post-test anxiety or depression scores above average receive extra attention during the counselling sessions.

The overall findings on anxiety, depression, and personality elicit optimism about predictive testing for HD. They should, however, not be merely generalised to the total at risk population. Indeed, psychometric testing in the pretest period ${ }^{6}$ showed that test participants are a self-selected group with good ego strength and positive coping strategies. Moreover, they received extensive pre- and post-test psychological counselling and support. Kessler ${ }^{11}$ suggested that the arduous testing protocols used by some centres may act as a screen to discourage all but the most motivated and determined people to proceed with the test. In Flanders, test participants have at least three counselling sessions and a neurological examination before they make the final decision and before a blood sample is taken. These elements may play a role in explaining the general low rate of high anxiety and depression one year after an unfavourable test result. Denial 
and minimisation of the impact of the result may be an additional explanation. ${ }^{19}{ }^{24}$ These psychological defence mechanisms give carriers the opportunity to adapt unconsciously to the painful information about the future. They are maladaptive if the test result is not integrated into daily life, for instance, in the decision making process about procreation.

The test did have a definite influence on family planning. Two thirds of the carriers with reproductive plans decided to refrain from having children or to have a prenatal diagnosis. Most non-carriers with reproductive plans had opted for a pregnancy. It is clear that their carrier status confronts the person with new problems and dilemmas in their reproductive decisions. Deciding to refrain from having children or to perform prenatal testing with a $50 \%$ risk of a pregnancy termination may indeed be very burdensome. The fact that one at risk woman was already pregnant before she received her result and that some others stopped contraception months before receiving the test result shows that reproductive decisions are very complex and subject to emotional and unconscious processes, especially in a genetic context. $^{24} 3334$

Pre- and post-test measures of general anxiety, depression, and ego strength were significantly intercorrelated. One coping strategy of the UCL (Depressive coping) and several MMPI scales (Hypochondriasis, Depression, Hysteria, and Social Introversion) were also significantly correlated with post-test general anxiety, depression level, and ego strength. The scales Hypochondriasis, Depression, and Hysteria are referred to as the "neurotic triad". ${ }^{29}$ The systematic correlation of this triad with the post-test anxiety, depression, and ego strength suggests that the more neurotic an at risk subject is before the test, the more anxious and the more depressive he will be after the test and the less ego strength he will have, whatever the result is.

Stepwise multiple regression analyses were used to select the best predictors from the pretest variables to predict individual post-test general anxiety, depression level, and ego strength. The analyses showed that post-test general anxiety was best predicted by a combination of the pretest ego strength and the pretest coping strategy comforting ideas. Coping by means of comforting ideas refers to encouraging oneself by inner speech and having generally optimistic thoughts. Post-test depression was best predicted by pretest depression level, measured with the BDI, and with the depression scale of the MMPI. A prediction of post-test depression level by means of pretest depression level (BDI) and the scale ego strength of the MMPI was nearly as good. Pretest ego strength was the single best predictor of post-test ego strength. Test outcome (carrier/non-carrier), gender, and age of the persons tested did not significantly contribute to the prediction of post-test trait anxiety, depression level, and ego strength. The reason for the lack of predictive power of the predictive test result is the large variation (SD) of pretest and post-test anxiety, depression, and ego strength scores and their large overlap in the carriers and non-carriers.

The results indicate that a careful evaluation of pretest depression, ego strength, and coping strategies may be helpful in predicting post-test reactions, independently of carrier status. They confirm the impact of ego strength in coping with a predictive test result. Barron ${ }^{12}$ suggested that people with higher ego strength may also profit more from counselling and psychotherapy than persons with lower ego strength.

The findings are also in line with the viewpoint of Wexler ${ }^{18}$ who argued that some at risk subjects would probably benefit more from psychotherapy than from a predictive test. The predictive test result had no additional predictive value in predicting individual reactions one year after the test. Other factors, such as pretest ego strength and depression, were more predictive. Therefore, it is important that depressive test participants or those with a low ego strength, who attribute all their fears and worries to their genetic risk, and who believe that all their problems will be solved after the test, should receive extra attention during pretest psychological counselling to anticipate and discuss possible remaining anxieties and difficulties, irrespective of the test result. Only a proportion of the variance of the post-test anxiety, depression, and ego strength (maximum $32 \%, 37 \%$, and $55 \%$, respectively) was explained, implying that other psychological/ social aspects should also be taken into account when predicting individual post-test reactions (for example, support of the partner, condition of the affected parent, survival guilt, uncertainty about the moment of onset of the disease).

Two critical remarks should be remembered when interpreting the findings. First, the role of the self-selection of the test participants and of the pre- and post-test psychological counselling should be kept in mind when interpreting mild post-test reactions, and pre- and post-test counselling and support should not be neglected as the test becomes more widely available. Second, we can not exclude that the low incidence of psychological problems is partly the result of a denial of distress. However, if this phenomenon was present, it did not occur to the extent that the predictive test result was not taken into account in reproductive decision making. Further systematic longitudinal follow up of carriers and non-carriers is needed, not only to provide psychological support to the tested person, but also to evaluate long term psychological and social effects of the predictive test.

1 Harper P. Huntington's disease. London: Saunders, 1991.

2 Gusella JF, Wexler NS, Conneally PM, et al. A polymorphic DNA marker genetically linked to Huntington's disease. Nature 1983;306:234-8.

3 Huntington's Disease Collaborative Research Group. A novel gene containing a trinucleotide repeat that is expanded and unstable on Huntington's disease chromoexpanded and unstable on

4 International Huntington Association and World Federation of Neurology. Guidelines for the molecular genetics predictive test in Huntington's disease. Neurology 1994; predictive test in Huntington's disease. Neurology 1994;
44:1533-6.

5 Evers-Kiebooms G. Predictive testing for Huntington's disease in Belgium. F Psychosom Obstet Gynecol 1990;11:6172 
6 Decruyenaere $M$, Kiebooms $\mathrm{G}$, Boogaerts A, et al. Predictive testing for Huntington's disease: risk perception, reasons for testing and psychological profile of test applicants. Genet Couns 1995;6:1-13.

7 Bloch M, Fahy M, Fox S, Hayden MR. Predictive testing for Huntington disease. II. Demographic characteristics, life-style patterns, attitudes, and psychosocial assessments of the first fifty-one test candidates. Am $\mathcal{F}$ Med Genet 1989 ; of the first

8 Tyler A, Ball D, Craufurd D. Presymptomatic testing for Huntington's disease in the United Kingdom. BMF 1992; Huntington's disease in the United Kingdom. BMF 1992;

9 Wiggins S, Whyte P, Huggins $M$, et al. The psychological consequences of predictive testing for Huntington's disease. $N$ Engl f Med 1992;327:1401-5.

10 Codori AM, Hanson R, Brandt J. Self-selection in predictive testing for Huntington's disease. Am $\mathcal{f}$ Med Gene 1994;54:167-73.

11 Kessler S. Predictive testing for Huntington disease: a psychologist's view. Am ₹ Med Genet 1994;54:161-6.

12 Barron F. An ego-strength scale which predicts response to psychotherapy. F Consult Clin Psychol 1953;17:327-33.

13 Babul R, Adam S, Kremer B, et al. Attitudes toward direct predictive testing for the Huntington Disease Gene. predictive testing for the Huntington Disease Gene. 270:2321-5.

14 Benjamin CM, Adam S, Wiggins S, et al. Proceed with care: direct predictive testing for Huntington disease. Am f Hum

15 Craufurd D, Dodge A, Kerzin-Storrar L, Harris R. Uptake of presymptomatic predictive testing for Huntington's disease. Lancet 1989;ii:603-5.

16 Bloch M, Adam S, Wiggins S, et al. Predictive testing for Huntington disease in Canada: the experience of those receiving an increased risk. Am $\mathcal{f}$ Med Genet 1992;42:499507.

17 Huggins M, Bloch M, Wiggins S, et al. Predictive testing for Huntington disease in Canada: adverse effects and unexpected results in those receiving a decreased risk. $\mathrm{Am}$ un Med Genet 1992;42:508-15.

18 Wexler N. The Tiresias complex: Huntington's disease as a paradigm of testing for late-onset disorders. FASEB $\mathscr{f}$ paradigm of t992;6:2820-5.

19 Codori AM, Brandt J. Psychological costs and benefits of predictive testing for Huntington's disease. $\mathrm{Am} \mathcal{F} \mathrm{Med}$

20 Quaid KA, Wesson MK. Exploration of the effects of predictive testing for Huntington disease on intimate relationships. Am $\mathcal{F}$ Med Genet 1995;57:46-51.
21 Derogatis LR. SCL-90-R: administration, scoring E procedures manual II for the revised version. Towson, 1983.

22 Beck AT, Ward CH, Mendelson M, et al. An inventory for measuring depression. Arch Gen Psychiatry 1961;4:56171.

23 Ware JE, Johnston SA, Davies-Avery A, Brook RH. Conceptualization and measurement of health for adults in the Health Insurance Study. Vol 3. Mental health. California: Rand, 1979.

24 Tibben A, Frets PG, Van de Kamp JJP, et al. On attitudes and appreciation 6 months after predictive DNA testing for Huntington's disease in the Dutch program. Am $\mathcal{F}$ Med Genet 1993;48:103-11.

25 Demyttenaere K, Evers-Kiebooms G, Decruyenaere M. Pitfalls in counseling for predictive testing in Huntington disease. In: Evers-Kiebooms G, Fryns JP, Cassiman JJ, Van den Berghe H, eds. Psychosocial aspects of genetic counseling. Vol 28. March of Dimes, Birth Defects. New York: WileyLiss, 1992:105-12.

26 Siegel S, Castellan, NJ. Nonparametric statistics for the behavioral sciences. 2nd ed. New York: McGraw-Hill, 1988.

27 Van der Ploeg HM, Defares PB, Spielberger CD. Handleiding bij de Zelfbeoordelingsvragenlijst: een Nederlandstalige bewerking van de Spielberger State Trait Anxiety Inventory. New York: Swets \& Zeitlinger, 1980.

28 Bouman TK, Luteijn F, Albertnagel FA, Van der ploeg FA. Enige ervaringen met de Beck Depression Inventory. Gedrag Tijdsch Psych 1985;13:13-24.

29 Graham JR. The MMPI. A practical guide. New York: Oxford University Press, 1987

30 Nuttin J, Beuten B. Handleiding bij de Persoonlijkheidsinventaris MMPI. Leuven: Studia Psychologica, 1969.

31 Schreurs PJ, Van de Willige G, Tellegen B, Brosschot JF. De Utrechtse Coping Lijst. Omgaan met problemen en gebeurtenissen. Lisse: Swets \& Zeitlinger, 1988.

32 Westbrook, MT. A classification of coping behavior based on multidimensional scaling of similarity rating. $\mathcal{F}$ Clin Psychol 1979;35:407-10.

33 Frets PG, Duivenvoorden HJ, Niermeijer MF, et al. Factors influencing the reproductive decision after genetic counseling. Am f Med Genet 1990;35:496-502.

34 Evers-Kiebooms G, Denayer L, Decruyenaere M, Van den Berghe $\mathrm{H}$. Community attitudes towards prenatal testing for congenital handicap. $\mathcal{J}$ Reprod Infant Psych 1993;11: $21-30$ 